\title{
Work engagement among breast cancer survivors and the referents: The importance of optimism and social resources at work
}

\author{
Jari J. Hakanen • Marja-Liisa Lindbohm
}

Received: 7 May 2008 / Accepted: 7 October 2008 /Published online: 21 November 2008

(C) The Author(s) 2008. This article is published with open access at Springerlink.com

\begin{abstract}
Introduction Despite a growing number of cancer survivors returning to work, little is known about their well-being at work and the work and personal characteristics related to it. The aim of the present study was to investigate personal resources (optimism and pessimism) and job-related resources (organizational climate, social support and avoidance behaviour) as antecedents of work engagement among female breast cancer survivors and their referents.

Methods A community-based postal survey was conducted among female breast cancer survivors and their referents. The final study population consisted of 398 employed survivors ( $86 \%$ response rate) and 560 of their referents (71\% response rate).

Results The level of work engagement was high in both study groups, although it was slightly higher among the referents than among the cancer survivors $(p<.05)$. Various social job resources were equally related to work engagement in both groups. However, optimism and pessimism were more strongly associated with work engagement among cancer survivors compared to the referents. In addition, in cancer survivors high optimism buffered against the negative impact of avoidance behaviour by supervisors on work engagement.
\end{abstract}

\section{J. J. Hakanen $(\bowtie)$}

Finnish Institute of Occupational Health, Work Organizations,

Topeliuksenkatu 41 a A,

FI-00250 Helsinki, Finland

e-mail: jari.hakanen@ttl.fi

M.-L. Lindbohm

Centre of Expertise for Health and Work Ability,

Finnish Institute of Occupational Health,

Helsinki, Finland
Conclusions Personal resources, such as optimism, may be especially important for cancer survivors' work-related well-being. On the other hand, social resources at work seem to be of similar salience to work engagement in cancer survivors and others.

Implication for cancer survivors Understanding the role of job resources and personal resources appears to be important in efforts to increase a cancer survivors' commitment to work life even more so than in those working with a out breast cancer history.

Keywords Cancer survivor - Breast cancer .

Work engagement · Job resources · Well-being at work · Optimism

\section{Introduction}

The increasing incidence of cancer and improvements in early detection and effective treatment of many cancer types have resulted in an increasing number of cancer survivors returning to work life. A large register-based study including all types of cancer showed that the employment rate of survivors 2-3 years after the diagnosis was $64 \%$, which was only slightly lower than the employment rate of their ageand gender-matched referents (73\%) [1]. There is, however, great variation in the rate of return to work between patients with different cancer types $[2,3]$.

The majority of cancer outcome research to date has focused on health-related quality of life assessment [4]. Another main target of research has been the effect of social support on the lives of cancer patients. Several studies have indicated that cancer survivors more often report workrelated impairment than non-cancer comparison group [3, 5-7]. There are, however, very few studies on cancer 
survivors' well-being at work. For example, in a 2004 review of studies on the impact of cancer on work outcomes not a single study had focused on aspects of work-related wellbeing [5]. Thus, knowledge of person-related and workrelated factors affecting the cancer survivors' well-being at work and potential differences in well-being between the survivors and other working population is scanty.

In this study we investigated well-being at work in terms of work engagement and individual and job-related resources associated with work engagement among female cancer survivors and their referents. More specifically, we examined whether optimism, pessimism and social job resources have a different role in work engagement for cancer survivors compared to their referents.

What is work engagement and how to promote it?

Traditionally, well-being at work has been mostly conceptualized and measured somewhat paradoxically in terms of ill-being, for example, job stress and burnout. Work engagement refers to truly positive well-being experiences at work. It has been defined as a positive, fulfilling, cognitive-affective state of mind at work characterized by vigor, dedication, and absorption [8]. Vigor refers to high levels of energy and mental resilience while working, the willingness to invest effort in one's work, and persistence in the face of difficulties. Dedication is characterized by a sense of significance, enthusiasm, inspiration, pride, and challenge. Finally, absorption refers to a sense of being fully concentrated and happily engrossed in one's work, so that time passes quickly and detaching oneself from work may seem difficult. Previous studies have consistently shown, for example, that work engagement is negatively related to withdrawal intentions from work [9] and positively to job and organizational commitment [10] and performance [11]. In addition, work engagement positively predicted personal initiative at work and work-unit innovativeness in a three-year longitudinal study among Finnish dentists [12].

According to the Job Demands - Resources model (JD $\mathrm{R}$ model) $[9,13]$ various job demands (e.g., time pressure, role conflicts) may lead to burnout, whereas job resources (e.g., social support at work, autonomy, and feedback) are especially salient for work engagement. Demerouti and her colleagues [13] have defined job resources as the physical, psychological, social, or organizational aspects of the job that not only reduce the negative effects of job demands and help to achieve work goals but may also stimulate personal growth, learning and development — and the positive state of work engagement. Studies so far have supported the assumption of the role of job resources as the prime antecedents of work engagement [9, 12, 14]. Moreover, job resources may also buffer the negative effects of job demands on work engagement and even boost work engagement, particularly under highly stressful conditions $[15,16]$.

It has been assumed that in addition to various job resources, personal resources may also foster work engagement [17]. Personal resources, such as self-efficacy, and optimism, are individual and at least partially acquired characteristics that may therefore be prone to change [18]. For example, in an experimental longitudinal study task resources positively predicted self-efficacy which, in turn, positively influenced work engagement [19]. In addition, Langelaan, Bakker, Van Doornen, and Schaufeli [20] found that extraversion was positively related to work engagement among Dutch employees.

On the basis of research literature, optimism can be regarded as one of the most salient personal resources. Optimism has been defined as the tendency to believe that one will generally experience good outcomes in life, whereas pessimists expect bad things to happen [21]. Optimists tend to use more active and problem-focused coping strategies than pessimists [22] and consequently also to adjust and cope better with serious disease such as breast cancer [23]. Traditionally, optimism has been viewed as a personality trait but more recently several researchers have emphasized that optimism also has a state component and that it can be learned and it is open to development [24].

Although to our knowledge the role of optimism in work engagement has not been studied previously, optimism is known to be associated with various psychological and physical well-being indicators, whereas pessimism has been associated with negative outcomes [25]. In addition, Riolli and Savick [26] showed in their study among information service employees that optimism moderated the impact of job resources on diminished personal accomplishment, i.e., one of the symptoms of burnout; when job resources (e.g., peer cohesion and supervisor support) were low, employees with higher optimism showed higher personal accomplishment compared to employees with lower optimism. In addition, when job resources were low, employees with higher pessimism showed, for example, higher levels of exhaustion compared with low pessimism employees.

Work and well-being among cancer survivors

The findings of a 2005 qualitative study indicated that work is an important contributor to cancer survivors' quality of life [27]. Work may have many positive effects for cancer survivors, although cancer and its treatment may reduce the ability to work. The proportion of survivors reporting impairment of work ability due to cancer has varied in different studies from about $20-30 \%$ [3]. According to a Finnish study, survivors who had received chemotherapy or had other diseases were more likely to report impaired work ability, whereas survivors with a strong commitment to 
their work organization, or good work climate, reported impairment less frequently [28]. When cancer survivors with a good prognosis were compared to a reference group selected from general population, no difference was observed in the self-assessed work ability or level of job strain between the two groups [28]. However, Hansen and her colleagues [7] found that breast cancer survivors reported more fatigue and depressive symptoms than the noncancer group. In addition, fatigue was more strongly related to work limitations (different job demands) among cancer survivors. In contrast, depressive symptoms of the comparison group were more strongly related to work limitations. To our knowledge there is only one previous study specifically focusing on the positive work-related affective state of well-being among cancer survivors [29]. In this paper, no clinically significant differences were found in work engagement between tumor-free cancer survivors and their referents [29].

\section{Optimism and work experience}

In this study, we investigated the role of job resources social support at work and organizational climate - and optimism (a personal resource) on work engagement among Finnish female breast cancer survivors and their matched reference group. We also included two measures of lacking ("negative") job resources: supervisor avoidance and colleague avoidance, which may be especially relevant aspects of job resources for cancer survivors. According to a recent study [30], breast cancer patients who had experienced discrimination because of their cancer were less likely to have returned to work at 12 months. In addition, we measured optimism and pessimism as separate concepts. Originally, optimism and pessimism were conceptualized as a bipolar construct in which they form opposite poles in the same continuum [21]. However, it has been argued that, for example, not being an optimist does not necessarily imply pessimism. Indeed, later research has supported the assumption that optimism and pessimism are distinct albeit negatively related constructs and that psychometrically measuring optimism and pessimism as separate dimensions (two factors) is more appropriate than a one-factor model in which both optimism and pessimism items are combined in the same scale [31-33].

Hence, in this study we compared the main and interaction effects of positive and negative job resources, optimism (and pessimism) in work-related well-being among cancer survivors and their referents. More specifically, we were interested in whether job resources and personal characteristics would be differently related to work engagement in these two groups. The theoretical model comprising the hypothesized relationships is depicted in Fig. 1.

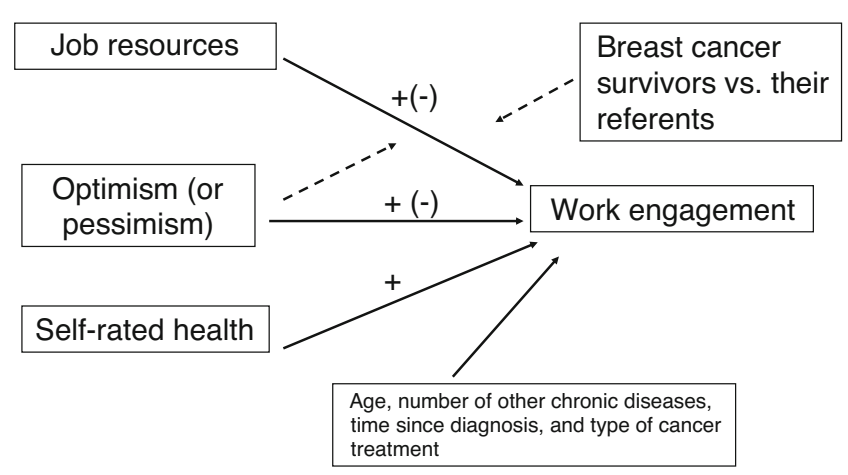

Fig. 1 Theoretical model.

\section{Methods}

Participants and procedure

The data were collected in connection with a Nordic questionnaire study on cancer and work life (NOCWO) [34]. The results presented in this article are based on the Finnish data on female breast cancer survivors. Altogether 620 female patients diagnosed with breast cancer in 1997 2001 were selected from the Patient Register of the Department of Oncology of the Helsinki University Hospital. The selected patients had to have a good prognosis (no advanced stage of disease or recurrence) and be 25-57 years of age at the time of the diagnosis. Other inclusion criteria were: no previous cancer, no ongoing treatment with cytostatic drugs, native language Finnish or Swedish, and resident of the Hospital District of Helsinki and Uusimaa, Finland. In addition, a reference group of 1,050 women was selected from the files of the Population Register Centre. The referents were selected randomly from the general population living in the same district and having the same age and gender distribution as the cancer survivors.

Questionnaires were mailed to the study subjects to obtain information on work engagement and related factors. A total of 531 breast cancer survivors (86\%) and 747 referents $(71 \%)$ completed the questionnaire. The analyses were restricted to those who were either employed full-time or part-time, worked as freelancers, or were self-employed at the time of the survey. The referents who reported having had cancer were excluded from the analyses ( 31 persons). The final study population comprised a total of 398 breast cancer survivors and 560 referents.

\section{Measures}

Job resources We measured four aspects of job resources. Two positive job resources scales were derived from the general Nordic Questionnaire (QPSNordic) which is a 
validated tool for measuring psychological and social factors at work [35]. Organizational climate was assessed with three items (e.g., "What is the climate like in your work unit?..encouraging and supportive"). Cronbach's alphas for cancer survivors were $\alpha_{\text {can }}=.78$ and for their referents $\alpha_{\text {ref }}=.83$. Social support at work was measured with five items on support from immediate supervisor and co-workers (e.g. "If needed, can you get support and help with your work from your co-workers?"). Cronbach's alphas were $\alpha_{\text {can }}=.87$ and $\alpha_{\text {ref }}=.86$. Both scales ranged from 1 (very seldom/little or not at all) to 5 (very often or always /very much) for all questions. In addition, two lacking (or "negative") job resources were developed for the present study. The measurement of discrimination was partly based on the Social Impact Scale, which was used in the study of Fife and Wright [36]. The specific questions were developed on the basis of a qualitative interview study carried out in Finland among 25 cancer survivors (unpublished data). Both avoidance behaviour by supervisor (e.g., "My supervisor avoids me") and avoidance behaviour by colleagues (e.g., "I feel isolated by my colleagues") were assessed with three items. Cronbach's alphas for avoidance behaviour by supervisor were $\alpha_{\text {can }}=.80$ and $\alpha_{\text {ref }}=.76$, and for avoidance behaviour by colleagues $\alpha_{\text {can }}=.82$ and $\alpha_{\text {ref }}=.68$, respectively. The items were rated on a five-point scale ranging from 1 (not at all) to 5 (very much). Exploratory factor analyses supported the distinctiveness of the four job resource scales.

Personal resources We used the revised Life Orientation Test (LOT-R) [22] to measure optimism and pessimism. The instrument consists of six items, three of which are positively phrased (e.g., "In uncertain times, I usually expect the best") and three negatively phrased to indicate pessimism (e.g., "I hardly ever expect things to go my way"). Confirmatory factor analyses showed that the two-factor structure (consisting of distinct optimism and pessimism factors) resulted in a significantly better model fit in both study groups compared with the one-factor structure (consisting of combined optimism/pessimism factor). Therefore, in this study we investigated separately optimism and pessimism. Cronbach's alphas for optimism were $\alpha_{\text {can }}=.80$ and $\alpha_{\text {ref }}=.74$, and for pessimism $\alpha_{\text {can }}=.74$ and $\alpha_{\text {ref }}=.68$, respectively. The items were rated on a five-point scale ranging from 1 (I disagree a lot) to 5 (I agree a lot).

Work engagement was assessed with the Finnish version of the Utrecht Work Engagement Scale (UWES) [8]. The validity of the Finnish version of UWES has been demonstrated in previous research [37]. The instrument includes three sub-scales: vigor, dedication, and absorption. Vigor was assessed with six items (e.g., "At my work, I feel bursting with energy"). Dedication was measured with five items (e.g., "I am enthusiastic about my job"). Finally, absorption was assessed with six items (e.g., "I am immersed in my work"). Cronbach's alphas for vigor were $\alpha_{\text {can }}=.86$ and $\alpha_{\text {ref }}=.87$; for dedication $\alpha_{\text {can }}=.92$ and $\alpha_{\text {ref }}=.93$; and for absorption $\alpha_{\text {can }}=.90$ and $\alpha_{\text {ref }}=.88$. The total work engagement scale comprised these three subscales $\left(\alpha_{\text {can }}=.95\right.$ and $\alpha_{\text {ref }}=.95$ ).

In addition to demographic information (age, educational level, marital status, employment status), the questionnaire contained questions on self-rated health and number of current chronic diseases or injuries diagnosed by a physician. These included injury or accident, musculoskeletal disease, cardiovascular disease, respiratory disease, mental disorder, neurological or sensory diseases, digestive disease, genitourinary disease, skin disease, tumour (asked only from the referents), endocrine and metabolic diseases, blood diseases, or other disorder or disease. Cancer-related information obtained from the hospital files included diagnosis, time since diagnosis, and treatment (classified into two categories: chemotherapy vs. some other type of treatment: endocrine therapy, radiotherapy and/or surgery).

\section{Data analysis}

We employed structural equation modeling (SEM) techniques using the AMOS 6.0 software package [38] to examine the study models in the two study groups. SEM offers certain advantages over more commonly used multiple regression analyses [39]. For example, by using latent variables ("factors") it is possible to assess and correct for measurement errors, which allows more reliable tests for the study models. In addition, SEM provides information on the degree of fit of the models, and thus it allows an exact test for alternative competing models to find a model that has best fit to the data. It is also possible to test differences in the strengths of the associations between different path coefficients. In a similar vein, it is possible to conduct multi-group comparison tests to compare model fits between the groups, which was of special importance in the present study.

We used several indicators for each latent variable ("factor") in the tested models. All latent job resource variables as well as optimism and pessimism were indicated by three items; work engagement was indicated by its subdimensions vigor, dedication, and absorption; and finally self-rated health and an interaction term (job resource $\mathrm{x}$ personal resource) were both indicated by one observed variable and their factor loadings were set to one. As a preliminary step, we first ran all the analyses separately with the cancer survivors so that it was possible to include the cancer-related variables as covariates in the models. Since the cancer-related variables did not significantly associate with other variables in the models, it was possible to remove them from the subsequent analyses and to 
conduct multi-group tests between cancer survivors and their referents with identical variables. Next we ran the analyses in both groups by including demographics and the number of current diagnosed diseases or injuries and selfrated health. Because only self-rated health was significantly related to work engagement, it was kept as a covariate in the final structural models.

Accordingly, we performed multi-group analyses by including in the structural model one (latent) job resource, one (latent) personal resource, and their interaction term at a time as independent (exogenous) variables, work engagement as a dependent (endogenous) variable, and self-rated health as a covariate in every model. As we wished to analyze four job resources and two personal resources, our analytical procedure consisted of eight multi-group model tests. In each test we compared the fit of a "free model," in which the regression paths and covariances were allowed to vary among cancer survivors and their referents, against a "constrained model," in which the paths and covariances were estimated as equal in the two groups. After finding the best fitting model, we used chi square model tests in a similar way to explore whether there were differences between the two groups in the strength of the association between a particular (job or personal) resource and work engagement. In other words, we tested whether job and personal resources were differently related to work engagement among cancer survivors compared to their referents. Moreover, in a series of tests we examined separately for the cancer survivor group and for the referent group whether a particular job resource was differently related to work engagement than a particular personal resource. Thus, it was possible to gain between and within group information on the possible differences in the role of job and personal resources in work engagement between the two groups.

In SEM several types of fit indices are used to assess and compare the fit of different models. In our study the Root Mean Square Error of Approximation (RMSEA), the Comparative Fit Index (CFI), the Tucker-Lewis Index (TLI), and the Normed Fit Index (NFI) were examined. Values smaller than.08 for the RMSEA are indicative of an acceptable fit, and values greater than 0.1 should lead to model rejection [40]. For CFI, NFI, and TLI, as a rule of thumb, values greater than .90 are considered to indicate a good fit [41]. We compared different competing nested models by means of chi-square difference test [42].

\section{Results}

\section{Descriptive statistics}

Table 1 shows that the cancer survivors were somewhat older (mean ages 51.5 years vs. 49.8 years) than their referents and
Table 1 Characteristics of the breast cancer survivors and their referent group

\begin{tabular}{|c|c|c|c|}
\hline Characteristic \% & $\begin{array}{l}\text { Cancer } \\
\text { survivors } \\
(N=398)\end{array}$ & $\begin{array}{l}\text { Referents } \\
(N=560)\end{array}$ & $x^{2}$ \\
\hline \multicolumn{4}{|l|}{ Age (years) } \\
\hline $25-39$ & 5 & 15 & \multirow[t]{4}{*}{$26.09 * * *$} \\
\hline $40-49$ & 23 & 22 & \\
\hline $50-59$ & 67 & 56 & \\
\hline$\geq 60$ & 5 & 7 & \\
\hline \multicolumn{4}{|l|}{ Educational level } \\
\hline $\begin{array}{l}\text { comprehensive school } \\
\text { (1-9 years) }\end{array}$ & 22 & 23 & \multirow[t]{4}{*}{0.19} \\
\hline $\begin{array}{l}\text { secondary /vocational school } \\
\text { (10-12 years) }\end{array}$ & 21 & 21 & \\
\hline college degree (13-16 years) & 32 & 32 & \\
\hline $\begin{array}{l}\text { higher university degree } \\
\text { (over } 16 \text { years) }\end{array}$ & 25 & 24 & \\
\hline \multicolumn{4}{|l|}{ Employment status } \\
\hline full-time employed & 81 & 80 & \multirow[t]{3}{*}{2.66} \\
\hline part-time employed & 13 & 11 & \\
\hline self-employed or entrepreneur & 6 & 9 & \\
\hline \multicolumn{4}{|l|}{ Marital status } \\
\hline married or co-habiting & 72 & 63 & \multirow[t]{2}{*}{$9.66^{* *}$} \\
\hline other & 28 & 37 & \\
\hline \multicolumn{4}{|c|}{ Number of current chronic diseases or injuries (other than cancer) } \\
\hline 0 & 54 & 52 & \multirow[t]{3}{*}{1.39} \\
\hline 1 & 33 & 36 & \\
\hline 2 & 13 & 12 & \\
\hline \multicolumn{4}{|l|}{ Time since diagnosis } \\
\hline 2 years ago & 23 & & \\
\hline $3-6$ years ago & 77 & & \\
\hline \multicolumn{4}{|l|}{ Treatment } \\
\hline no chemotherapy & 53 & & \\
\hline chemotherapy & 47 & & \\
\hline
\end{tabular}

$* * * p<.001 ; * * p<.01$

the cancer survivors were also more likely to be married or co-habiting. However, there were no differences in educational level, employment status or in the number of current chronic diseases or injuries between the two groups. The frequencies of different types of chronic diseases were also similar among the survivors and the referents. Fifty percent of the female cancer survivors had had chemotherapy. In $46 \%$ of the cases, the tumor size had been small $(<2 \mathrm{~cm})$, in $12 \% 2-5 \mathrm{~cm}$ with no metastasis; $39 \%$ of the patients had had metastasis to only $1-3$ regional lymph nodes.

The comparison of the mean levels of the main variables in the study indicated that the groups did not differ in relation to the four job resources, optimism, pessimism, and self-rated health (Table 2). Both groups reported high levels of work engagement, although work engagement among the reference group was somewhat higher than among the cancer survivors $(4.74$ vs. $4.56, p<.05)$. The small difference in the mean levels of work engagement remained statistically 
Table 2 Mean scores of self-rated health, job resources, optimism, pessimism, and work engagement and t-tests for differences among cancer survivors $(N=398)$ and their referents $(N=560)$

\begin{tabular}{|c|c|c|c|c|c|}
\hline & \multicolumn{2}{|c|}{ Cancer survivors } & \multicolumn{2}{|c|}{ Referents } & \multirow[t]{2}{*}{$t$-test } \\
\hline & M & $\mathrm{SD}$ & M & SD & \\
\hline Self-rated health & 3.98 & .73 & 4.03 & .74 & .82 \\
\hline Social support at work & 4.01 & .81 & 4.07 & .81 & 1.19 \\
\hline Organizational climate & 3.70 & .84 & 3.70 & .90 & .00 \\
\hline Supervisor avoidance & 1.27 & .56 & 1.32 & .61 & 1.76 \\
\hline Colleague avoidance & 1.25 & .50 & 1.31 & .53 & 3.72 \\
\hline Optimism & 3.81 & .73 & 3.83 & .69 & .07 \\
\hline Pessimism & 2.29 & .79 & 2.27 & .74 & .14 \\
\hline Work engagement & 4.56 & 1.21 & 4.74 & 1.09 & $5.26^{*}$ \\
\hline
\end{tabular}

$* p<.05$.

significant even after controlling for the effects of demographic factors and self-rated health $(\mathrm{F}(1)=5.53, p<.05)$.

Cancer-related and other background variables correlated only marginally or not at all with the study variables (Table 3). In both groups job resources, optimism, and self-rated health were positively associated with work engagement, whereas lacking job resources and pessimism were negatively related to work engagement. However, both optimism and pessimism were more strongly associated with work engagement among cancer survivors than among their referents.

Structural relationships between job and personal resources and work engagement

Each of the eight tested models consisted of a particular job resource, a particular personal resource, their interaction term, self-rated health, and work engagement, and the models were fitted simultaneously in the cancer survivor and in the referent groups. As a first step, we examined whether there were differences between the groups regarding the study models (Table 4). We found that all of the models showed good fit to the data. However, in seven out of eight model comparisons the "free model" showed significantly $(p<$. 05, five comparisons) or marginally $(p<.10$, two comparisons) better fit to the data than the "constrained model." This means that in most models there were group-based differences in the associations between job and personal resources, self-rated health, and work engagement. As an exception, the relationships between optimism, supervisor avoidance, self-rated health, and work engagement were equal among cancer survivors and their referents. Figures 2 and 3 are examples of the final structural models presented in Table 4 and in Table 5.

In the next step, we further compared separate path coefficients (1) between the groups and (2) within a group to detect potential differences in the associations between job and personal resources and work engagement in the best fitting models as reported in Table 4. Again, these analyses were conducted by comparing a "free model" (path coefficients were allowed to vary) and a "constrained model" (path coefficients were constrained to be equal). Table 5 shows, first, that in every (eight) model comparison job resources were as strongly associated with work engagement among cancer survivors as in the referent group. Second, in seven out of eight models optimism and pessimism were more strongly associated with cancer survivors' work engagement than to the referents' work engagement. Moreover, pessimism was not statistically related to work engagement among the non-cancer group.

Third, we found an interaction effect (st. $\beta=.11, p<.05$ ) between optimism and avoidance behaviour by supervisor on work engagement but only among cancer survivors (Table 5). Figure 4 shows the direction of the interaction effect: high optimism in cancer survivors buffered against the negative impact of avoidance behaviour by supervisors

Table 3 Intercorrelations between study variables among breast cancer survivors $(N=398)$ and their referents $(N=560)$

\begin{tabular}{|c|c|c|c|c|c|c|c|c|c|c|c|c|}
\hline Variable & 1 & 2 & 3 & 4 & 5 & 6 & 7 & 8 & 9 & 10 & 11 & 12 \\
\hline 1. Age & - & $.19 * * *$ & $-.19 * * *$ & $-.21 * * *$ & -.05 & $-.11 *$ & -.08 & .08 & .06 & -.04 & $.11^{*}$ & -.03 \\
\hline 2. Other chronic diseases & $.25 * * *$ & - & -.04 & -.05 & $-.40 * * *$ & -.09 & $-.12 *$ & .10 & $.14^{* *}$ & $-.11 *$ & .05 & -.09 \\
\hline 3. Treatment $^{1}$ & - & - & - & .03 & -.04 & .02 & -.01 & .02 & .03 & -.03 & .06 & -.06 \\
\hline 4. Time since diagnosis & - & - & - & - & .01 & .08 & .02 & -.08 & $-.12 *$ & .01 & .02 & -.01 \\
\hline 5. Self-rated health & $-.12 * *$ & $-.41 * * *$ & - & - & - & $.17 * *$ & $.22 * * *$ & $-.21 * * *$ & $-.26 * * *$ & $.33 * * *$ & $-.26^{* * *}$ & $.35^{* * *}$ \\
\hline 6. Social support at work & -.02 & -.07 & - & - & $.13 * *$ & - & $.59 * * *$ & $-.49 * * *$ & $-.40 * * *$ & $.25 * * *$ & $-.26^{* * *}$ & $.32 * * *$ \\
\hline 7. Organizational climate & -.08 & $-.11 *$ & - & - & $.21 * * *$ & $.63 * * *$ & - & $-.47 * * *$ & $-46^{* * *}$ & $.27 * * *$ & $-.24 * * *$ & $.30 * * *$ \\
\hline 8. Supervisor avoidance & .01 & $.10^{*}$ & - & - & $-.15 * *$ & $-.58 * * *$ & $-.45^{* * *}$ & - & $.61 * * *$ & $-.21 * * *$ & $.21 * * *$ & $-.29 * * *$ \\
\hline 9. Colleague avoidance & .06 & $.18^{* * *}$ & - & - & $-.19 * * *$ & $-.45^{* * *}$ & $-.44 * * *$ & $.49 * * *$ & - & $-.19 * * *$ & $.22 * * *$ & $-.27 * * *$ \\
\hline 10. Optimism & -.00 & $-.11 *$ & - & - & $.23 * * *$ & $.26^{* * *}$ & $.24 * * *$ & $-.18 * * *$ & $-.24 * * *$ & - & $-.50 * * *$ & $.49 * * *$ \\
\hline 11. Pessimism & .05 & $.18^{* * *}$ & - & - & $-.20 * * *$ & $-.15^{* *}$ & $-.17 * * *$ & $.15^{* *}$ & $.21 * * *$ & $-.47 * * *$ & - & $-.34 * * *$ \\
\hline 12. Work engagement & .06 & -.02 & - & - & $.21 * * *$ & $.35 * * *$ & $.31 * * *$ & $-.23 * * *$ & $-.21 * * *$ & $.26^{* * *}$ & $-.13 * *$ & - \\
\hline
\end{tabular}

Intercorrelations above the diagonal refer to cancer survivors and below the diagonal to their referents. ${ }^{*} p<.05 ; *^{*} p<.01 ; * * * p<.001$.

${ }^{1} 1=$ other treatment (than chemotherapy); $2=$ chemotherapy 
Table 4 Fit statistics for the study models and multi-group comparison of model differences among breast cancer survivors $(N=398)$ and their referents $(N=560)$

\begin{tabular}{|c|c|c|c|c|c|c|c|c|c|c|c|}
\hline Model & $\begin{array}{l}\text { Individual disposition and job resource } \\
\text { in the model }\end{array}$ & $x^{2}$ & $\mathrm{df}$ & GFI & CFI & NFI & TLI & RMSEA & $\begin{array}{l}\text { Model } \\
\text { comparison }\end{array}$ & $\Delta \chi^{2}$ & $\Delta \mathrm{df}$ \\
\hline$M 1_{\text {free }}$ & optimism and organizational climate & 187.97 & 78 & .96 & .97 & .95 & .95 & .043 & $\mathrm{M} 1_{\text {constr }}$ vs. & $14.84^{*}$ & 7 \\
\hline M1 $1_{\text {constr }}$ & & 202.80 & 85 & .95 & .96 & .94 & .95 & .043 & $\mathrm{M} 1_{\text {free }}$ & & \\
\hline $\mathrm{M} 2_{\text {free }}$ & optimism and social support & 533.80 & 120 & .91 & .91 & .89 & .88 & .068 & $\mathrm{M} 2_{\text {constr }}$ vs. & $15.45^{*}$ & 7 \\
\hline $\mathrm{M} 2_{\text {constr }}$ & & 549.26 & 127 & .91 & .90 & .88 & .88 & .067 & $\mathrm{M} 2_{\text {free }}$ & & \\
\hline$M 3_{\text {free }}$ & optimism and supervisor avoidance & 162.06 & 78 & .96 & .97 & .95 & .96 & .038 & M3 $3_{\text {constr }}$ vs. & 10.59 & 7 \\
\hline M3 $3_{\text {constr }}$ & & 172.65 & 85 & .96 & .97 & .94 & .96 & .037 & $\mathrm{M} 3_{\text {free }}$ & & \\
\hline $\mathrm{M} 4_{\text {free }}$ & optimism and colleague avoidance & 199.29 & 78 & .96 & .96 & .94 & .94 & .046 & M4 constr vs. & $13.29^{\mathrm{a}}$ & 7 \\
\hline M4 $4_{\text {constr }}$ & & 212.58 & 85 & .95 & .96 & .93 & .94 & .045 & $\mathrm{M} 4_{\text {free }}$ & & \\
\hline $\mathrm{M}_{\text {free }}$ & pessimism and organizational climate & 205.79 & 78 & .95 & .96 & .94 & .94 & .047 & M5 $5_{\text {constr }}$ vs. & $15.62 *$ & 7 \\
\hline M5 $5_{\text {constr }}$ & & 221.41 & 85 & .95 & .96 & .93 & .94 & .046 & $\mathrm{M} 5_{\text {free }}$ & & \\
\hline$M 6_{\text {free }}$ & pessimism and social support & 540.08 & 120 & .91 & .90 & .88 & .87 & .068 & $\mathrm{M}_{\text {constr }}$ vs. & $18.33^{*}$ & 7 \\
\hline M6 $6_{\text {constr }}$ & & 558.41 & 127 & .91 & .90 & .87 & .88 & .067 & $M 6_{\text {free }}$ & & \\
\hline $\mathrm{M} 7_{\text {free }}$ & pessimism and supervisor avoidance & 233.75 & 78 & .95 & .95 & .93 & .93 & .052 & $\mathrm{M} 7_{\text {constr }}$ vs. & $12.87^{\mathrm{a}}$ & 7 \\
\hline M7 constr & & 246.62 & 85 & .94 & .94 & .92 & .93 & .050 & $\mathrm{M} 7_{\text {free }}$ & & \\
\hline $\mathrm{M} 8_{\text {free }}$ & pessimism and colleague avoidance & 255.79 & 78 & .94 & .94 & .92 & .92 & .055 & M8 $8_{\text {constr }}$ vs. & $15.19^{*}$ & 7 \\
\hline M8 $8_{\text {constr }}$ & & 270.98 & 85 & .94 & .94 & .91 & .92 & .054 & $\mathrm{M} 8_{\text {free }}$ & & \\
\hline
\end{tabular}

$* p<.05 ;{ }^{\mathrm{a}}<.10$

on work engagement. Instead, supervisor avoidance was more strongly negatively related to the work engagement of cancer survivors with low levels of optimism. In a similar vein, optimism and organizational climate also had a marginal joint effect (st. $\beta=-.09, p<.10$ ) on cancer survivors' work engagement. Figure 5 shows that respondents with high optimism seemed to stay engaged regardless of organizational climate, whereas good organizational

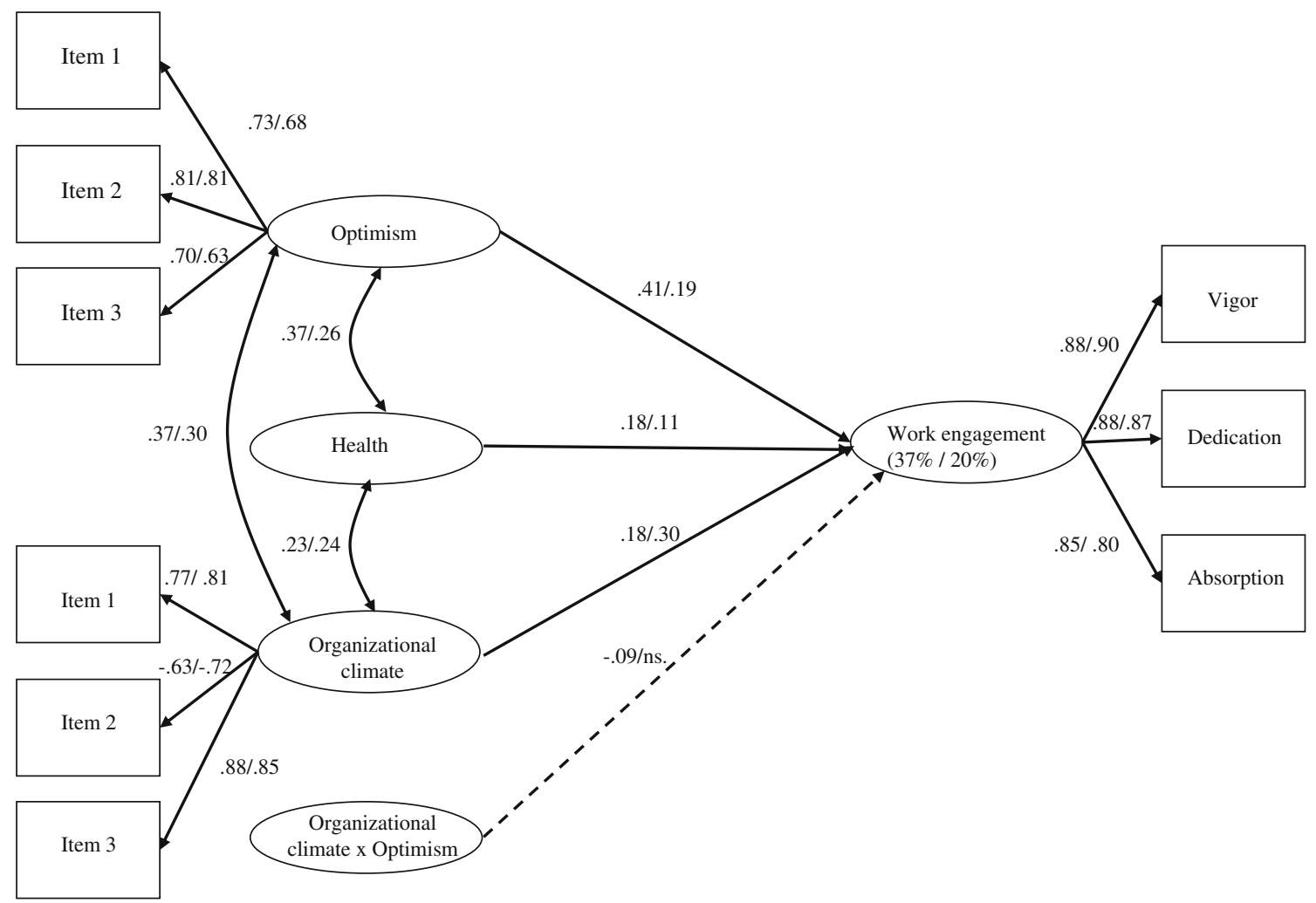

Fig. 2 The associations between organizational climate at work, optimism, their interaction, self-rated health, and work engagement among breast cancer survivors and their referents; an example of a final structural model. Numbers on the left refer to the breast cancer survivors and the numbers on the right to the referents. The explained variances of work engagement are in parentheses. 


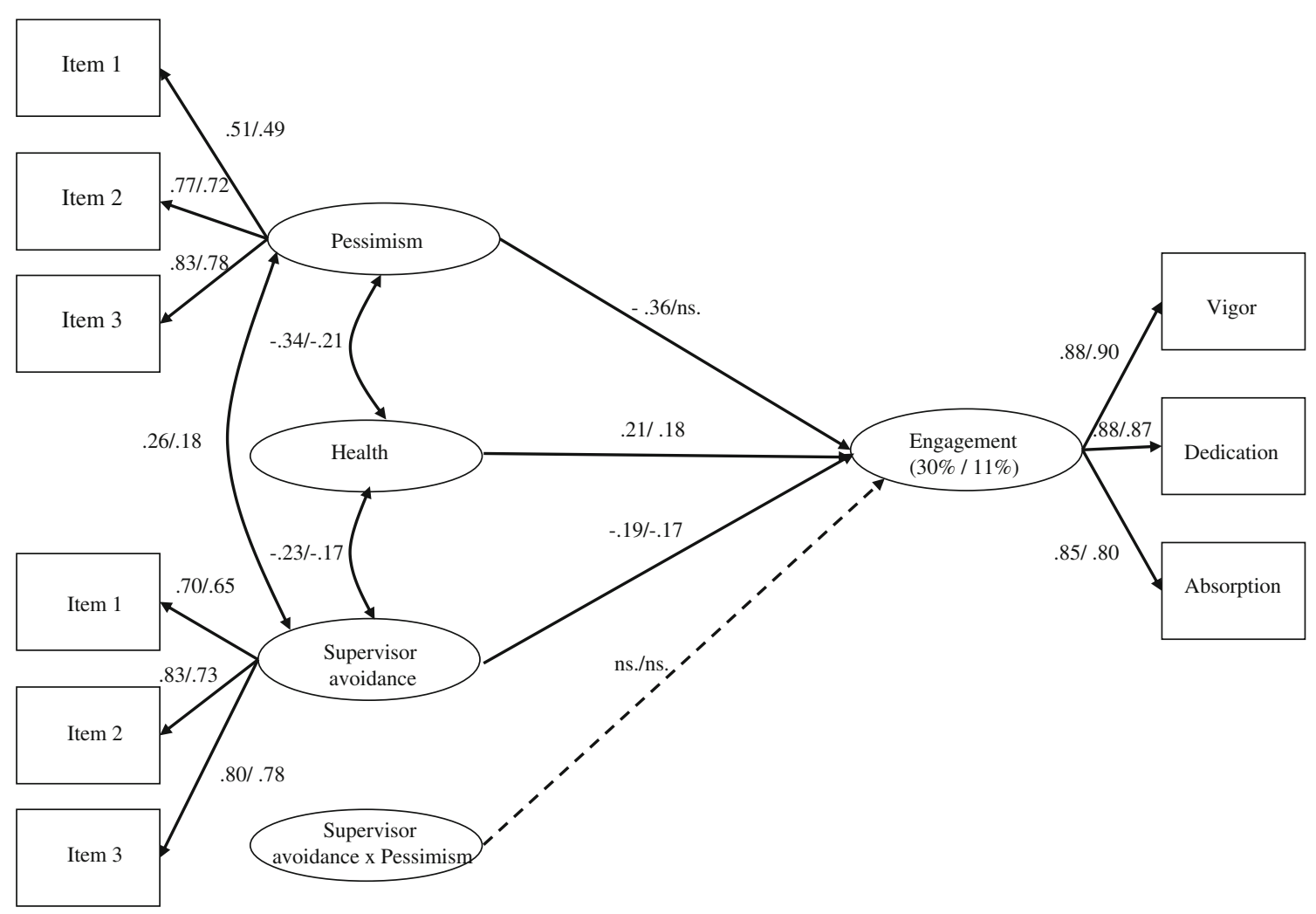

Fig. 3 The associations between supervisor avoidance behavior, pessimism, their interaction, self-rated health and work engagement among breast cancer survivors and their referents; an example of a

climate was especially beneficial for the work engagement of low optimism cancer survivors.

Fourth, within group comparisons showed that the strength of the association between optimism and work engagement was consistently stronger than the association between a particular job resource and work engagement but only among cancer survivors. Such difference was not found with the referents. In their case, optimism and job resources were equally strongly associated with work engagement. On the other hand, in every comparison pessimism and job resources were equally strongly related to work engagement among cancer survivors, whereas only job resources (but not pessimism) were related to work engagement among the referents. Finally, because optimism and pessimism were more strongly related to work engagement among cancer survivors than among their referents, the variance of work engagement explained by each model was also clearly stronger in cancer survivors than in the referents, as can be seen in Table 5 .

\section{Discussion}

The present cross-sectional study focused on work engagement and its potential antecedents: job resources, optimism final structural model. Numbers on the left refer to the breast cancer survivors and the numbers on the right to the referents. The explained variances of work engagement are in parentheses.

and pessimism among female breast cancer survivors. By using a referent group for the cancer survivors and by measuring both positive (social support at work and organizational climate) and negative/lacking (supervisor and colleague avoidance behaviour) aspects of job resources and personal characteristics it was possible to gain a more comprehensive view on cancer survivors' work-related wellbeing, which so far has been a sparsely investigated area of research.

The importance of optimism and pessimism for work engagement

The results showed that both job and personal resources were related to work engagement even after controlling for the effect of self-rated health, although the pattern and strength of the associations were partly different between cancer survivors and their referents as shown by a series of structural equation modeling analyses. A major finding of this study was that both optimism and pessimism were of greater importance to cancer survivors' work engagement than to that of their referents. This finding was indicated (1) by comparing the strength of the relationships between job resources and work engagement and between optimism/ pessimism and work engagement separately in the two 
Table 5 Standardized maximum likelihood estimates of path coefficients and their statistically significant differences between the two groups and within the groups for the best fitting models. As for group comparisons, the estimates on the left refer to the cancer survivors and on the right to the referent group

\begin{tabular}{|c|c|c|c|c|c|c|c|}
\hline \multirow[t]{2}{*}{ Model } & \multirow{2}{*}{$\begin{array}{l}\text { Individual } \\
\text { disposition and } \\
\text { job resource in the } \\
\text { model }\end{array}$} & \multicolumn{3}{|c|}{ Comparing the associations between the groups } & \multicolumn{3}{|c|}{ Comparing the associations within the group } \\
\hline & & $\begin{array}{l}\text { Job } \\
\text { resource } \rightarrow \\
\text { Engagement }\end{array}$ & $\begin{array}{l}\text { Optimism/ } \\
\text { Pessimism } \\
\rightarrow \text { Engagement }\end{array}$ & $\begin{array}{l}\text { Optimism/ } \\
\text { Pessimism x Job } \\
\text { resource } \rightarrow \\
\text { Engagement }\end{array}$ & $\begin{array}{l}\text { Job resource vs. } \\
\text { Optimism/Pessimism } \\
\text { among cancer } \\
\text { survivors }\end{array}$ & $\begin{array}{l}\text { Job resource vs. } \\
\text { Optimism/ } \\
\text { Pessimism among } \\
\text { the referents }\end{array}$ & $\begin{array}{l}\text { Explained variance } \\
\text { of work } \\
\text { engagement } \\
\text { in the models }\end{array}$ \\
\hline$M 1_{\text {free }}$ & $\begin{array}{l}\text { optimism and } \\
\text { organizational } \\
\text { climate }\end{array}$ & .18 vs. .30 & .41 vs. $.19 *$ & $-.09^{\mathrm{a}}$ vs. ns. & .18 vs. $.41 * *$ & .30 vs. .19 & $37 \%$ vs. $20 \%$ \\
\hline $\mathrm{M} 2_{\text {free }}$ & $\begin{array}{l}\text { optimism and } \\
\text { social support }\end{array}$ & .19 vs. .29 & .41 vs. $.21 *$ & ns. vs. ns. & .19 vs. $.41 *$ & .29 vs. .21 & $37 \%$ vs. $21 \%$ \\
\hline $\mathrm{M} 3^{\text {constr }}$ & $\begin{array}{l}\text { optimism and } \\
\text { supervisor } \\
\text { avoidance }\end{array}$ & -.13 vs. -.19 & .43 vs. .25 & $.11 *$ vs. ns. & -.13 vs. $.43^{*}$ & -.19 vs. .25 & $34 \%$ vs. $16 \%$ \\
\hline $\mathrm{M} 4_{\text {free }}$ & $\begin{array}{l}\text { optimism and } \\
\text { colleague } \\
\text { avoidance }\end{array}$ & -.16 vs. -.18 & .46 vs. $.22 *$ & ns. vs. ns. & -.16 vs. $.46^{*}$ & -.18 vs. .22 & $36 \%$ vs. $15 \%$ \\
\hline $\mathrm{M} 5_{\text {free }}$ & $\begin{array}{l}\text { pessimism and } \\
\text { organizational } \\
\text { climate }\end{array}$ & .22 vs. .33 & -.30 vs. ns. ${ }^{*}$ & ns. vs. ns. & .22 vs. -.30 & .33 vs. ns. ${ }^{* * *}$ & $31 \%$ vs. $17 \%$ \\
\hline$M 6_{\text {free }}$ & $\begin{array}{l}\text { pessimism and } \\
\text { social support }\end{array}$ & .21 vs. .32 & -.30 vs. ns. ${ }^{*}$ & ns. vs. ns. & .21 vs. -.30 & .32 vs. ns. ${ }^{* *}$ & $31 \%$ vs. $17 \%$ \\
\hline $\mathrm{M} 7_{\text {free }}$ & $\begin{array}{l}\text { pessimism and } \\
\text { supervisor } \\
\text { avoidance }\end{array}$ & -.19 vs. -.20 & -.33 vs. ns. ${ }^{* *}$ & ns. vs. ns. & -.19 vs. -.33 & -.20 vs. ns. & $30 \%$ vs. $11 \%$ \\
\hline $\mathrm{M} 8_{\text {free }}$ & $\begin{array}{l}\text { pessimism and } \\
\text { colleague } \\
\text { avoidance }\end{array}$ & -.15 vs. -.22 & -.34 vs. ns. ${ }^{* *}$ & ns. vs. ns. & -.15 vs. -.34 & -.22 vs. ns. * & $30 \%$ vs. $12 \%$ \\
\hline
\end{tabular}

Note 1. ns. refers to a non-significant estimate.

Note 2. Statistically significant differences between (path coefficients of) the strengths of the associations, ${ }^{* * *} p<.001 ;{ }^{* *} p<.01 ;{ }^{*} p<.05 ; \mathrm{a}<.10$

groups and (2) by comparing the strength of these relationships simultaneously between the two groups. The results showed that cancer survivors' optimism was more strongly positively related to work engagement than the job resources available to them were and this relationship was also stronger than the corresponding relationship in the referent

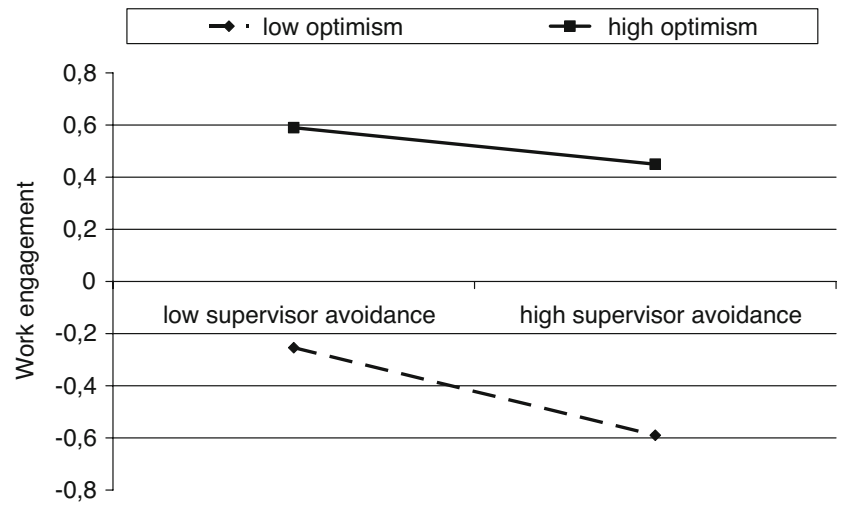

Fig. 4 Interaction effect $(p<.05)$ of optimism and supervisor avoidance on work engagement among breast cancer survivors. group. Similarly, cancer survivors' pessimism was more strongly, albeit negatively, related to work engagement than their perceived job resources, whereas among the referents, pessimism was not associated with work engagement.

Although to our knowledge there are no previous studies on work-related well-being and optimism among cancer

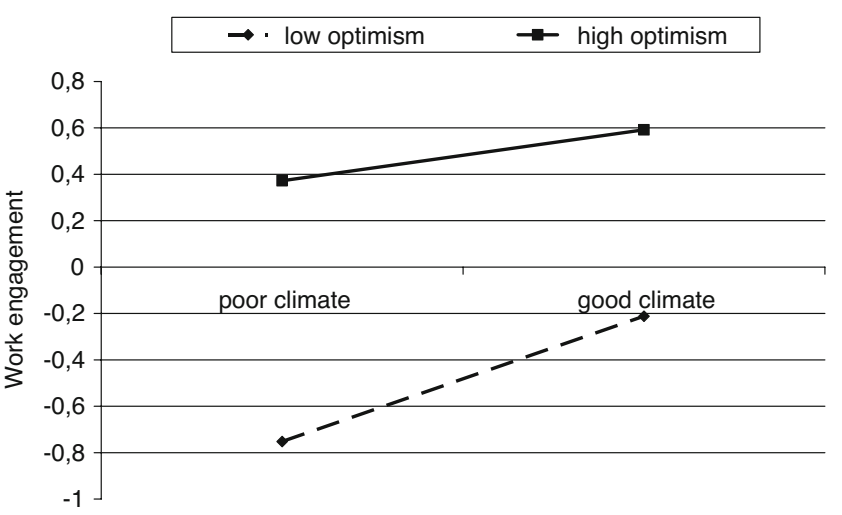

Fig. 5 Marginal interaction effect $(p<.10)$ of optimism and organizational climate on work engagement among breast cancer survivors. 
survivors, other studies on cancer patients have shown the salience of optimism and pessimism for well-being and health. For example, Stiegelis and her colleagues [43] found that optimism of cancer patients positively predicted lower level of anxiety over time. Similarly, Carver and his research group [23] found that pessimism was positively and optimism negatively associated with distress among breast cancer patients throughout the first postoperative year. More generally, optimism has been linked to different positive psychological and physical well-being indicators whereas pessimism has been linked to negative outcomes [25], suggesting that optimism may function as a real resource promoting well-being and health. Furthermore, according to the results of the present study, optimism (and pessimism) may be of particular salience for cancer survivors who have returned to work.

The role of job resources in work engagement

Although personal characteristics were especially associated with cancer survivors' work engagement, this study showed that also job resources, i.e., those aspects of the job that help to achieve work goals and also stimulate personal growth, learning and development [13] are closely related to a positive state of work engagement. Good organizational climate and social support from one's immediate supervisor and colleagues (i.e., job resources) were positively related to work engagement, whereas supervisor and colleague avoidance behaviour (i.e., lacking job resources) were negatively associated with work engagement. The strength of these associations was equal in both groups in every tested (eight) model. Somewhat similar findings were obtained in a study among brain tumour survivors [6]. They experienced higher levels of work limitations than the comparison group, but the factors related to work limitations did not differ between the two groups.

In contrast to, for example task-level job resources (task variety, results of the job etc; see for example [12]), our instruments of job resources concerned social-level resources at work. Previous studies among cancer survivors have also found support for the positive relationship between social support and positive work outcomes. For example, supportive work environment has been reported to facilitate return to work [2]. In addition, social support from colleagues was related to a reduced risk of impaired work ability among women in a previous study with the same dataset as the present study [28]. Unexpectedly, a recent Norwegian study found that social support from colleagues at work was associated with reduced work engagement in a population including cancer survivors and a reference group from the general population [29].

An innovation of this study was to supplement real job resources with "negative" job resources, i.e., aspects of the job that may hinder the achievement of work goals and overall performance in the job and gradually erode employee's energies and engagement with work. In our study, avoidance and isolating behaviour by one's colleagues or supervisor were negatively related to work engagement in both groups. Bouknight and his colleagues [30] found in their study that discrimination was not a widespread problem for breast cancer patients in their sample. However, those who had experienced discrimination because of their cancer were significantly less likely to return to work at 12 months. Feuerstein et al. [44] observed that claims related to job loss and terms of employment were more likely in cancer survivors than employees with other types of impairments, although the percentage of cancer survivors who file claims was relatively small. It is noteworthy that our results showed that general (not necessarily related to cancer) experiences of avoidance were equally common among cancer survivors and referents and avoidance behaviour was as strongly associated with work engagement in both groups.

We also found some indications of joint effects between job and personal characteristics on work engagement but only among cancer survivors: The cancer survivors who were more optimistic stayed engaged regardless of the level of supervisor avoidance and organizational climate. However, not experiencing avoidance behaviour by one's supervisor on the one hand, and perceiving nice and supportive organizational climate on the other, seemed to be especially beneficial for the work engagement of low optimism cancer survivors. In other words, the association between these two types of job resources and work engagement were strongest when the cancer survivors reported low levels of optimism.

Optimism has been related to the use of more active coping strategies when managing stressful events [25]. Optimistic employees may, for example, find other forms of supportive resources in the workplace [45]. In contrast, the results suggest that for the work engagement of low optimism cancer survivors, the quality of work climate and supervisor behaviour may be of greater importance. For example, good organizational climate may compensate somewhat for the lack of personal resources, in this case optimism. However, it should be kept in mind that out of eight possible interactions among cancer survivors these two were the only ones detected.

Health and work engagement

Previously, work engagement has been consistently found to relate to indicators of organizational commitment and job performance [9, 10-12]. Although we did not specifically focus on the role of self-rated health in this study but, instead, used perceived health status rather as a covariate in our statistical analyses, the present study found support for 
the positive association between health and work engagement. Some other studies have also found work engagement to be positively related to different health indicators [37, 46]. Recently, Parzefall and Hakanen [47] found that engagement fully mediated the impact of psychological contract fulfilment on mental health. Future studies with longitudinal designs are needed to explore whether health may positively contribute to work engagement or vice versa or whether the relationship could even be reciprocal.

\section{Strengths and limitations}

An important strength of our study was the inclusion of a reference group, enabling us to separate cancer-specific effects from those resulting from other factors. The response rate was also high, $86 \%$ among the cancer survivors and $71 \%$ among the referents. In addition, our study on well-being focused on truly positive experiences at work in terms of work engagement, not on the negative experiences of stress or burnout.

This study has certain limitations. First, all the measures were based on self-reports thus causing a concern for common method bias (i.e., bias resulting from shared variance in the measurement that is attributed to the instrumentation rather than to the association between the constructs). On the other hand, we investigated both positive and negative job resources and personal characteristics, and the results were consistent irrespective of the direction of items. Thereby in this study it was possible to diminish the risk for positive or negative bias at least to some extent. However, including, for example, more objective measures of working conditions in future studies on work engagement for cancer survivors would strengthen the study design.

Second, work engagement was somewhat lower among the cancer survivors than among the referents and no difference was found in optimism between the two groups. It has been suggested that a response shift altering the definition of health in a cancer survivor or inducing the development of coping style involving denial or minimization of distress inflates self-reported psychological wellbeing relative to physical health among some survivors [48]. The potential effect of this self-deception response bias is likely to be small for our findings, because the reference group also included subjects with some other serious chronic disease probably affecting similarly their reports on well-being. However, it should be kept in mind that both cancer survivors and the referents reported rather high levels of work engagement and the difference in the mean level of work engagement between the groups was minor.

Third, the present study included only cross-sectional information on the relationships between job and personal characteristics and work-related well-being. Prospective and longitudinal studies beginning as closely as possible to the time of cancer diagnosis are needed to assess both short-term and long-term impact of cancer on work-related issues [5].

Fourth, we only focused on female breast cancer survivors. Moreover, we had no information on the use of antidepressants or other medications that may affect, for example, the level of optimism. In future studies, the wellbeing at work among survivors with other types of cancer and poorer prognosis as well as male cancer survivors should also be investigated. In addition, the potential confounding impact of medications should be examined.

Fifth, in this study we investigated job resources and work engagement among cancer survivors and their referents. In future studies on cancer survivors' well-being at work, including items on job demands, i.e., work stressors, and measures assessing ill-health at work, for example, burnout in the questionnaire would be useful.

\section{Conclusions}

All in all, our results showed that female breast cancer survivors may be highly engaged in their work, report a similar level of social job resources, and be as optimistic (or pessimistic) as their non-cancer referents. Both job and personal resources were relevant for work engagement (characterized by vigor, dedication, and absorption at work) among cancer survivors and the referents. However, optimism and pessimism were clearly more strongly related to employee well-being among cancer survivors.

The present findings underline the importance of fostering a good climate, supportive co-worker relationships, and encouraging and supportive leadership practices, on the one hand, and avoidance of isolating and discriminating behaviour in the workplace, on the other. Since in our study these job resources were equally important to work engagement regardless of whether one had had cancer or not, workplace (or individual) interventions aiming to improve job resources perhaps do not necessarily need to focus specifically on cancer survivors. Instead, fostering job resources may benefit the whole workplace. The present study and previous studies on job resources and work engagement are highly suggestive that fostering job resources and employee engagement may have positive consequences for both the individuals and the organization.

Acknowledgements The study was supported by the Nordic Cancer Union (NCU), the Finnish Work Environment Fund, and Finnish Cancer Organisations. We thank Taina Taskila for her contribution to the designing of the study and data collection.

Open Access This article is distributed under the terms of the Creative Commons Attribution Noncommercial License which permits any noncommercial use, distribution, and reproduction in any medium, provided the original author(s) and source are credited. 


\section{References}

1. Taskila-Åbrandt T, Martikainen R, Virtanen S, Pukkala E, Hietanen $\mathrm{P}$, Lindbohm M-L. The impact of education and occupation on the employment status of cancer survivors. Eur J Cancer. 2004;40:2488-93. doi:10.1016/j.ejca.2004.06.031.

2. Spelten ER, Sprangers MA, Verbeek JH. Factors reported to influence the return to work of cancer survivors: a literature review. Psycho-Oncology. 2002;11:124-31. doi:10.1002/pon.585.

3. Taskila T, Lindbohm M-L. Factors affecting cancer survivors' employment and work ability. Acta Oncologica (Stockholm, Sweden). 2007;46:446-51. doi:10.1080/02841860701355048.

4. Gotay CC, Lipscomb J, Snyder CF. Reflections on findings of the cancer outcomes measurement working group: moving to the next phase. J Natl Cancer Inst. 2005;97:1568-74.

5. Steiner JF, Cavender TA, Main DS, Bradley CJ. Assessing the impact of cancer on work outcomes - what are the research needs? Cancer. 2004;101:1703-11. doi:10.1002/cncr.20564.

6. Feuerstein M, Hansen JA, Calvio LC, Johnson L, Ronquillo JG. Work productivity in brain tumor survivors. J Occup Environ Med. 2007;49:803-11. doi:10.1097/JOM.0b013e318095a458.

7. Hansen JA, Feuerstein M, Calvio LC, Olsen CH. Breast cancer survivors at work. J Occup Environ Med. 2008;50:777-84.

8. Schaufeli W, Salanova M, González-Roma V, Bakker AB. The measurement of engagement and burnout: a two sample confirmatory factor analytic approach. Journal of Happiness Studies. 2002;3:71-92. doi:10.1023/A:1015630930326.

9. Schaufeli W, Bakker AB. Job demands, job resources, and their relationship with burnout and engagement. J Organ Behav. 2004;25:293-315. doi:10.1002/job.248.

10. Hakanen JJ, Bakker A, Schaufeli W. Burnout and engagement among teachers. J Sch Psychol. 2006;43:495-513. doi:10.1016/j. jsp.2005.11.001.

11. Salanova M, Agut S, Peiró JM. Linking organizational facilitators and work engagement to employee performance and customer loyalty: the mediation of service climate. J Appl Psychol. 2005;90:1217-27. doi:10.1037/0021-9010.90.6.1217.

12. Hakanen JJ, Perhoniemi R, Toppinen-Tanner S. Positive gain spirals at work: from job resources to work engagement, personal initiative, and work-unit innovativeness. J Vocat Behav. 2008;73:78-91. doi:10.1016/j.jvb.2008.01.003.

13. Demerouti E, Bakker AB, Nachreiner F, Schaufeli WB. The job demands-resources model of burnout. J Appl Psychol. 2001;86:499-512. doi:10.1037/0021-9010.86.3.499.

14. Mauno S, Kinnunen U, Ruokolainen M. Job demands and resources as antecedents of work engagement: a longitudinal study. J Vocat Behav. 2007;70:149-71. doi:10.1016/j.jvb.2006.09.002.

15. Bakker A, Hakanen J, Demerouti E, Xanthopoulou D. Job resources boost work engagement, particularly when job demands are high. J Educ Psychol. 2007;99:274-84. doi:10.1037/00220663.99.2.274.

16. Hakanen JJ, Bakker A, Demerouti E. How dentists cope with their job demands and stay engaged: the moderating role of job resources. Eur J Oral Sci. 2005;113:479-87. doi:10.1111/j.16000722.2005.00250.x.

17. Bakker A, Demerouti E. The job demands-resources model: state of the art. J Manag Psychol. 2007;22:309-28. doi:10.1108/ 02683940710733115 .

18. Xanthopoulou D, Bakker AB, Demerouti E, Schaufeli WB. The role of personal resources in the job demands-resources model. Int Stress Manag. 2007;14:121-41. doi:10.1037/1072-5245.14.2.121.

19. Llorens S, Schaufeli W, Bakker A, Salanova M. Does a positive gain spiral of resources, efficacy beliefs and engagement exist? Comput Hum Behav. 2007;23:825-41. doi:10.1016/j.chb.2004.11.012.
20. Langelaan S, Bakker AB, Van Doornen LJP, Schaufeli WB. Burnout and work engagement: do individual differences make a difference? Pers Individ Differ. 2006;40:521-32. doi:10.1016/j. paid.2005.07.009.

21. Scheier MF, Carver CS. Optimism, coping, and health: assessment and implications of generalized outcome expectancies. Health Psychol. 1985;4:219-47. doi:10.1037/0278-6133.4.3.219.

22. Scheier MF, Carver CS, Bridges MW. Distinguishing optimism from neuroticism (and trait anxiety, self-mastery, and self-esteem): a reevalutation of the life orientation test. J Pers Soc Psychol. 1994;67:1063-78. doi:10.1037/0022-3514.67.6.1063.

23. Carver CS, Pozo C, Harris SD, Noriega V, Scheier MF, Robinson DS, et al. How coping mediated the effect of optimism on distress: a study of women with early stage breast cancer. J Pers Soc Psychol. 1993;65:375-90. doi:10.1037/0022-3514.65.2.375.

24. Luthans F, Youssef CM, Avolio BJ. Psychological capital: Investing and developing positive organizational behavior. In: Nelson DL, Cooper CL, editors. Positive organizational behavior. London: Sage; 2007. p. 9-24.

25. Scheier MF, Carver CS. Effects of optimism on psychological and physical well-being: theoretical overview and empirical update. Cogn Ther Res. 1992;16:201-28. doi:10.1007/BF01173489.

26. Riolli L, Savicki V. Optimism and coping as moderators of the relationship between work resources and burnout in information service workers. Int J Stress Manag. 2003;10:235-52. doi:10.1037/1072-5245.10.3.235.

27. Main DS, Nowels CT, Cavender TA, Etschmaier M, Steiner JF. A qualitative study of work and work return in cancer survivors. Psycho-Oncology. 2005;14:992-1004. doi:10.1002/pon.913.

28. Taskila T, Martikainen R, Hietanen P, Lindbohm M-L. Comparative study of work ability between cancer survivors and their referents. Eur J Cancer. 2007;43:914-20. doi:10.1016/j.ejca. 2007.01.012.

29. Gudbergsson SB, Fosså SD, Dahl AA. Is cancer survivorship associated with reduced work engagement? A NOCWO study. Journal of Cancer Survivorship. 2008; doi:10.1007/s11764-0080059-9

30. Bouknight RR, Bradley CJ, Luo Z. Correlates of return to work for breast cancer survivors. J Clin Oncol. 2006;24:345-53. doi:10.1200/JCO.2004.00.4929.

31. Benyamini Y. Can high optimism and high pessimism co-exist? Findings from arthritis patients coping with pain. Pers Individ Differ. 2005;38:1463-73. doi:10.1016/j.paid.2004.09.020.

32. Chang L, McBride C. The factor structure of the life orientation test. Educ Psychol Meas. 1996;56:325-29. doi:10.1177/ 0013164496056002013

33. Kubzansky LD, Kubzansky PE, Maselko J. Optimism and pessimism in the context of health: bipolar opposites or separate constructs? Personality and Social Psychology Bulletin. 2004;30:943-56. doi:10.1177/0146167203262086.

34. Gunnarsdottir HK, Rafnsdottir GL, Bernburg JG, Lindbohm M-L. Employment participation and work experience of female breast cancer and lymphoma survicors from the Nordic Study of Cancer and Work (NOCWO). In: Torres VN, editor. Lung cancer in women. New York: Nova Science Inc; 2007. p. 335-57.

35. Elo A-L, Dallner M, Gamberale L, Hottinen V, Knardahl S, Lindström K, et al. User's guide for the QPSNordic: general Nordic questionnaire for psychological and social factors at work. Copenhagen: Nordic Council of Ministers; 2001.

36. Fife BL, Wright ER. The dimensionality of stigma: a comparison of its impact on the self of persons with HIV/AIDS and cancer. J Health Soc Behav. 2000;41:50-67. doi:10.2307/2676360.

37. Hakanen JJ. Työuupumuksesta työn imuun - positiivisen työhyvinvointikäsitteen ja -menetelmän suomalaisen version validointi opetusalan organisaatiossa [From burnout to job engagement validation of the Finnish version of an instrument for measuring 
job engagement (UWES) in an educational organization]. Työ ihminen. 2002;16:42-58.

38. Arbuckle JL. Amos 6.0 user's guide. Chigago: SPSS Inc; 2005.

39. Baron RM, Kenny DA. The moderator-mediator variable distinction in social psychological research: conceptual, strategic, and statistical considerations. J Pers Soc Psychol. 1986;51(6):117382. doi:10.1037/0022-3514.51.6.1173.

40. Browne MW, Cudeck R. Alternative ways of assessing model fit. In: Long JS, editor. Testing structural equation models. Newbury Park: Sage; 1993. p. 136-62.

41. Hoyle RH. The structural equation modeling approach: Basic concepts and fundamental issues. In: Hoyle RH, editor. Structural equation modeling, concepts, issues, and applications. Thousand Oaks: Sage; 1995. p. 1-15.

42. Jöreskog KG, Sörbom D. LISREL user guide version VI. 4th ed. Mooresville: Scientific Software International; 1986.

43. Stiegelis HE, Hagedoorn M, Sanderman R, van der Zee KI, Buunk BP, van den Bergh ACM. Cognitive adaptation: a comparison of cancer patients and healthy references. $\mathrm{Br} \mathrm{J}$
Health Psychol. 2003;8:303-18. doi:10.1348/1359107033223 70879.

44. Feuerstein M, Luff GM, Harrington CB, Olsen CH. Pattern of workplace disputes in cancer survivors: a population study of ADA claims. Journal of Cancer Survivorship. 2007;1:185-92. doi:10.1007/s11764-007-0027-9.

45. Mäkikangas A, Kinnunen U. Psychosocial work stressors and well-being: self-esteem and optimism as moderators in a one-year longitudinal sample. Pers Individ Differ. 2003;35:537-57. doi:10.1016/S0191-8869(02)00217-9.

46. Hallberg U, Schaufeli WB. "Same same" but different? Can work engagement be discriminated from job involvement and organizational commitment? Eur Psychol. 2006;11:119-27. doi:10.1027/ 1016-9040.11.2.119.

47. Parzefall M, Hakanen JJ. Psychological contract and its motivational and health-enhancing outcomes. J Manag Psychol, in press.

48. O Leary TE, Diller L, Recklitis CJ. The effects of response bias on self-reported quality of life among childhood cancer survivors. Qual Life Res. 2007;16:1211-20. doi:10.1007/s11136-007-9231-3. 